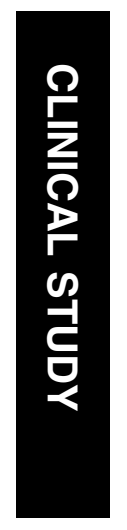

'Department of Ophthalmology, University of Brescia, Brescia, Italy

${ }^{2}$ Department of Ophthalmology, Glaucoma Unit, 1st University,

Thessaloniki, Greece

${ }^{3}$ San Paolo Hospital, Eye Clinic, University of Milan, Milan, Italy

${ }^{4}$ Hospital Clinico San Carlos, Madrid, Spain

${ }^{5}$ Eye Clinic, Mater Misericordiae University Hospital, Dublin, Ireland

${ }^{6} \mathrm{G}$. B. Bietti

Foundation-Istituto di Ricovero e Cura a Carattere Scientifico, Rome, Italy

${ }^{7}$ Charleston Research Company, Charleston, LLC, SC, USA

${ }^{8}$ PRN Pharmaceutical Research Network, LLC, Charleston, SC, USA

Correspondence:

WC Stewart,

PRN Pharmaceutical

Research Network, LLC, 6296 Rivers Avenue, Suite 309, Charleston, SC 29406, USA

Tel: + 1843762 6500;

Fax: + 18437627444

E-mail: info@

prnorb.com

Received: 19 May 2009 Accepted in revised form: 5 October 2009

Published online: 4

December 2009

\section{Untreated 24-h intraocular pressures measured with Goldmann applanation tonometry vs nighttime supine pressures with Perkins applanation tonometry}

L Quaranta', AGP Konstas ${ }^{2}$, L Rossetti ${ }^{3}$,

J Garcia-Feijoo ${ }^{4}$, C O'Brien ${ }^{5}$, MB Nasr²,

P Fogagnolo ${ }^{6}, \mathrm{CM}$ Demos $^{7}$, JA Stewart ${ }^{8}$ and WC Stewart ${ }^{8}$

\begin{abstract}
Aims To compare supine nighttime intraocular pressure measurements with Perkins applanation tonometry to 24-h sitting intraocular pressures with Goldmann applanation tonometry.

Methods A prospective, untreated, uncontrolled, observational cohort of qualified consecutive ocular hypertensive or primary open-angle glaucoma patients. Patients underwent sitting intraocular pressure measurements over 24-h by Goldmann and patients had their supine nighttime intraocular pressure measurements by Perkins.
\end{abstract}

Results In 100 completed patients, the mean intraocular pressure at 1000, 2200, 0200 and 0600 hours while sitting was $22.5 \pm 3.7 \mathrm{~mm} \mathrm{Hg}$, and in the supine position, $23.5 \pm 4.3 \mathrm{~mm} \mathrm{Hg}$ $(P<0.001)$. The mean sitting Goldmann intraocular pressures across the three daytime points was $23.3 \pm 3.4 \mathrm{~mm} \mathrm{Hg}$ and across three nighttime points was $21.5 \pm 4.0 \mathrm{~mm} \mathrm{Hg}$ $(P<0.001)$. In contrast, the mean daytime sitting Goldmann intraocular pressure was not different than the mean nighttime supine intraocular pressure evaluated with Perkins (22.8 $\pm 4.4 \mathrm{~mm} \mathrm{Hg}, P=0.07)$. However, only $70 \%$ of patients were within $1.0 \mathrm{~mm} \mathrm{Hg}$ of the highest daytime reading for all nighttime supine and sitting intraocular pressures. Conclusion This study suggests that with Perkins applanation tonometry the untreated mean supine intraocular pressures are not higher at night than daytime sitting Goldmann applanation tonometry. However, the highest daytime sitting intraocular pressure measurement does not consistently predict the highest nighttime sitting or supine intraocular pressure value.

Eye (2010) 24, 1252-1258; doi:10.1038/eye.2009.300; published online 4 December 2009

Keywords: 24-h intraocular pressures; Goldmann tonometry; nighttime supine intraocular pressures; Perkins tonometry

\section{Introduction}

Historically, it has been thought that the intraocular pressure generally is higher during the daytime than in the nighttime and this was believed to be due to the lower aqueous production at night. ${ }^{1-3}$ Most published 24-h pressure studies have evaluated sitting intraocular pressures with Goldmann applanation tonometry soon after awakening and support that intraocular pressure is generally higher in the daytime compared with nighttime. ${ }^{4-18}$ However, most of these 24-h studies, although not all, had been performed in elderly patients treated with anti-glaucomatous medicine.

In contrast, some data have shown higher pressures in untreated patients at night compared with daytime values. ${ }^{1}$ The reason 
for these differences is not known precisely. However, this difference may be due to the measurement technique used by these investigators, which consisted of pneumotonometry while patients were sleeping in a supine position. ${ }^{19}$

Consequently, controversy still exists whether intraocular pressure is higher in the daytime or nighttime and what is the best method to measure nighttime intraocular pressures. Unfortunately, little prior data are available that describe using the Goldmann technique in the supine position (eg Perkins applanation tonometry) during nighttimes hours. ${ }^{20}$

The primary objective of this multi-centre study was to use Perkins tonometry to measure nighttime supine intraocular pressures and to compare these values to day and nighttime sitting intraocular pressures measured by Goldmann tonometry.

\section{Materials and methods}

\section{Patients}

The study design was a prospective, untreated, uncontrolled, observational cohort, which lasted 16 months. There were five clinical sites with considerable experience in performing 24-h pressure monitoring collaborating for this study. The necessary Ethics Committee approval was obtained. The study population consisted of patients at least 18 years of age with either ocular hypertension or primary open-angle glaucoma. Ocular hypertension was defined as a pressure $\geqslant 22 \mathrm{~mm} \mathrm{Hg}$ without signs of glaucomatous optic disc or visual field damage. In contrast, primary open-angle glaucoma was defined generally as those patients with open, normal appearing anterior chamber angles per gonioscopy and with typical glaucomatous optic atrophy (neural rim thinning, notching, saucerization, or nerve fibre layer disc haemorrhage) and typical glaucomatous visual field damage (arcuate, Seidel's or paracentral scotoma or nasal step). ${ }^{21,22}$

We excluded from this study patients who showed abnormalities preventing reliable applanation tonometry in the study eye, any opacity or patient

uncooperativeness that restricts adequate examination of the ocular fundus or anterior chamber in either eye, any concurrent infectious/noninfectious conjunctivitis, keratitis, or uveitis in either eye, any ocular infection or inflammation within 1 month of Visit 1, any clinically significant, serious, or severe medical (including psychiatric) condition, participation (or current participation) in any investigational drug or device trial within the earlier 30 days before the screening visit, earlier intraocular laser or intraocular surgical procedures, inability to understand the trial procedures, and thus inability to give informed consent, and any progressive retinal or optic nerve disease apart from glaucoma and occludable angles as determined by indentation gonioscopy.

\section{Procedures}

Qualified patients, after signing an informed consent document, underwent a screening examination at Visit 1, including Snellen visual acuity, slit lamp biomicroscopy, and Goldmann tonometry. Patients that were treated then underwent an appropriate washout period of their current ocular hypotensive medication(s) and were scheduled to return for Visit 2. This included 6 weeks for both prostaglandin analogues and $\beta$-blockers. ${ }^{23-25}$

At Visit 2, patients with pressures of $\geqslant 22 \mathrm{~mm} \mathrm{Hg}$ at 1000 hours in at least one eye underwent a 24 -h pressure curve evaluation. This included pressure measurements at 1000 hours by Goldmann tonometry in a sitting position and immediately followed by Perkins tonometry in a supine position. Pressure measures with the Perkins were limited primarily to nighttime, as the primary purpose of this study was to compare nighttime supine pressures with daytime and nighttime sitting pressures. Nighttime is when patients generally are in a recumbent position. The calibration had been checked within 6 months. We chose Perkins tonometry because it uses the same applanation method as Goldmann tonometry and the two techniques have been well correlated in the past, although several studies have shown small mean differences between the two tonometers. ${ }^{26-30} \mathrm{We}$ performed Perkins tonometry at 1000 hours to correlate the daytime measure with the Goldmann, which was used to measure the pressure in the sitting position. The models of tonometers used for the study were HaagStreit (Bern, Switzerland), Clement Clarke MK2 (Harlow, England), and Kowa HA2 (Kowa, Japan).

Concomitant administrations of cardiac or antihypertensive medications were recorded, and Snellen visual acuity was measured. Corneal thickness measurements were not measured prospectively, but were collected historically, if available. After these baseline data were collected, further daytime sitting pressures were recorded by Goldmann tonometry at 1400 and 1800 hours.

Sleep times were left to the individual subject. Nighttime pressures were evaluated at an in-patient unit. At 2200 hours patients underwent Perkins tonometry in a supine position. Patients then were taken to a nearby slit lamp in which Goldmann tonometry was performed. At 0200 and 0600 hours patients were awakened from sleep and Perkins tonometry in a supine position was performed immediately. Again, patients were taken as soon as possible to a nearby slit lamp with which Goldmann tonometry was measured. Every effort was 
made to measure sitting and supine pressures in the study at the same time point within $5 \mathrm{~min}$ of each other. At each site and time point, the same person measured both the sitting and supine pressures. The use of Perkins and Goldmann tonometry was not masked in this study. After the 24-h pressure measurements, and barring any unresolved adverse events, patients were discontinued from the study.

\section{Statistics}

A per protocol, average eye (mean of the group), and twoway analysis were used. A $P$-value of 0.05 was used to declare statistical significance between groups. A sample of 100 subjects, assuming a standard deviation of $3.0 \mathrm{~mm} \mathrm{Hg}$ in the change of pressures between groups, provided a power of $80 \%$ to exclude $0.9 \mathrm{~mm} \mathrm{Hg}$ difference between groups. ${ }^{11,31,32}$ Both eyes were included in the study.

A one-way ANOVA test, using a matched pairs platform, was used to describe mean differences between sitting and supine pressures and daytime and nighttime pressures over multiple time points and at each individual time point. ${ }^{33}$ Because of the multiple measures at individual time points, a modified Bonferroni correction was used to adjust the $P$-value to declare significance $(\alpha / 2)$. A one-way ANOVA test was used also to describe mean differences between groupings of time points to describe differences in sitting daytime and nighttime pressures. ${ }^{33}$

The number of patients who had evening sitting or supine pressures above their peak daytime pressure and adverse events were described and not evaluated statistically.

\section{Results}

\section{Patient characteristics and safety}

In total, 100 patients completed this 24-h study. Included in the study were 94 Caucasians, one Hispanic, one African American, and four of unknown race. In addition, 51 were male and 49 female, and the average age was $57.3 \pm 23.6$ years. Further, 65 patients had ocular hypertension and 35 were diagnosed with primary open-angle glaucoma. At Visit 1, 27 patients were being treated with prostaglandins $(n=10), \beta$-blockers $(n=12)$, $\alpha$-agonists $(n=1)$, or adjunctive therapy $(n=4)$, whereas 73 were untreated. There were no early discontinuations or adverse events during this study.

\section{Intraocular pressure - sitting vs supine}

The intraocular pressure results are shown in Table 1 and Figure 1. The mean intraocular pressures at 1000, 2200,
Table 1 Mean intraocular pressures - sitting and supine $(\mathrm{mm} \mathrm{Hg})$

\begin{tabular}{lcccc}
\hline Visit & Time point & Sitting IOP & Supine IOP & P-values \\
\hline Visit 1 & & $24.8 \pm 3.4$ & & \\
Visit 2 & $10: 00$ & $24.6 \pm 3.4$ & $25.4 \pm 4.0$ & $<0.006$ \\
& $14: 00$ & $23.4 \pm 3.4$ & & \\
$18: 00$ & $22.8 \pm 3.5$ & & \\
$22: 00$ & $21.7 \pm 3.9$ & $22.6 \pm 4.3$ & $<0.006$ \\
& $02: 00$ & $20.4 \pm 3.9$ & $22.0 \pm 4.5$ & $<0.006$ \\
& $06: 00$ & $22.3 \pm 4.2$ & $23.9 \pm 4.5$ & 0.3 \\
& \multicolumn{4}{l}{ Mean change between Goldmann and Perkins } \\
\hline
\end{tabular}

Abbreviation: IOP, intraocular pressure.

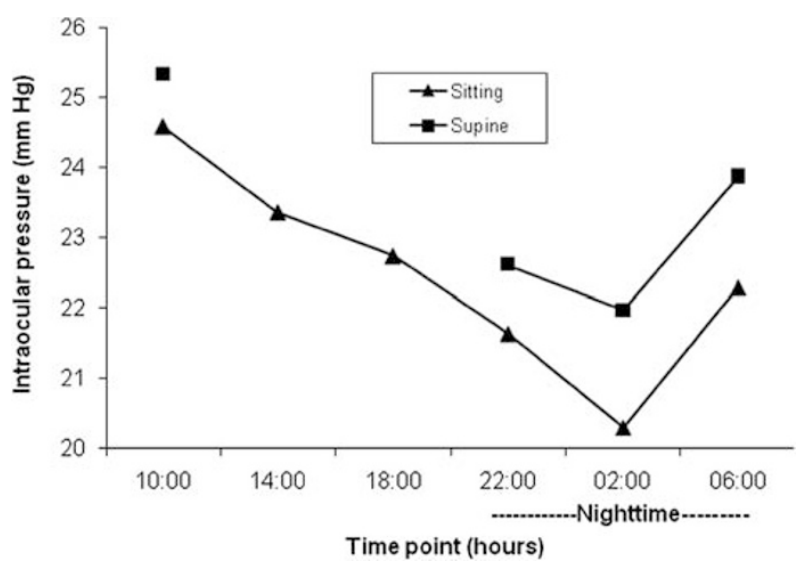

Figure 1 Intraocular pressure results for sitting and supine position.

0200, and 0600 hours while sitting was $22.2 \pm 3.8 \mathrm{~mm} \mathrm{Hg}$, and in the supine position, $23.5 \pm 4.3 \mathrm{~mm} \mathrm{Hg}(P<0.006)$. Further, the pressure was significantly different between sitting and supine groups at three individual time points (1000, 2200, and 0200 hours, $P \leqslant 0.006$ ), but not at 06:00 h $(P=0.3)$. Glaucoma patients had a mean change of $22.7 \pm 3.5$ to $23.6 \pm 4.0 \mathrm{~mm} \mathrm{Hg}$ from sitting to a supine position, whereas ocular hypertensives had a mean change of $22.5 \pm 3.6$ to $23.4 \pm 4.4 \mathrm{~mm} \mathrm{Hg}$ from sitting to a supine position $(P=0.07)$, which was not significantly different between groups.

\section{Intraocular pressure - daytime vs nighttime}

The mean sitting Goldmann intraocular pressure across three daytime time points (1000, 1400, and 1800 hours) was $23.6 \pm 3.4 \mathrm{~mm} \mathrm{Hg}$ and across three nighttime time points (2200, 0200, and 0600 hours) was $21.5 \pm 4.0 \mathrm{~mm} \mathrm{Hg}$ $(P<0.001)$. Table 2 shows that the great majority of patients had their peak sitting pressure in the daytime and their trough sitting pressure most often at night. In contrast, the mean daytime Goldmann pressures were 
not statistically different than nighttime supine Perkins pressures $(22.8 \pm 4.4 \mathrm{~mm} \mathrm{Hg}, P=0.07)$.

Table 3 shows how well the highest daytime pressure predicts nighttime sitting or supine measurements at various pressure levels. The table indicates that $\sim 70 \%$ of patients, for both their right and left eye, were within $1.0 \mathrm{~mm} \mathrm{Hg}$ of the highest sitting daytime reading for nighttime pressures. Further, the table indicates that $\sim 75 \%$ of patients were within $1.0 \mathrm{~mm} \mathrm{Hg}$ of the highest daytime sitting or a single supine reading for nighttime pressures $(P>0.40)$.

\section{Discussion}

Prior studies have shown that patients in the supine position may have higher intraocular pressures than in the sitting position of between 0.4 to $3.6 \mathrm{~mm} \mathrm{Hg}{ }^{21}$ The intraocular pressure in the supine position may have its most clinical relevance at night when the patient is either recumbent and awake or supine and asleep. Knowledge of a patient's nighttime supine pressures may have

Table 2 Peak and trough intraocular pressures $(\mathrm{mm} \mathrm{Hg})$

\begin{tabular}{lccc}
\hline Time point & $\begin{array}{c}\text { Patients with } \\
\text { peak IOP at } \\
\text { time point }(\%)^{\mathrm{a}}\end{array}$ & $\begin{array}{c}\text { Patients with } \\
\text { trough IOP at } \\
\text { time point (\%) }\end{array}$ \\
\hline Daytime & $10: 00$ & 19 & 10 \\
Nighttime & $14: 00$ & 85 & 0 \\
& $18: 00$ & 32 & 0 \\
& $22: 00$ & 8 & 31 \\
& $02: 00$ & 3 & 61 \\
& $06: 00$ & 12 & 18
\end{tabular}

Abbreviation: IOP, intraocular pressure.

${ }^{a}$ The same peak pressures may have occurred at more than one time point. importance in several ways: first, in assessing the adequacy of a patient's intraocular pressure control, and second, in explaining why some patients may have progressive glaucomatous optic neuropathy despite apparently well-controlled daytime pressures.

A problem exists, however, that the gold standard for measuring intraocular pressure, Goldmann tonometry, requires the patient to be in a sitting position. Controversy exists, then, regarding the best measure for the intraocular pressure in the supine position. Both commercially available Perkins tonometer and pneumotonometer have been described for this purpose. Perkins tonometry has the advantage of using the basic Goldmann technology. ${ }^{20}$ The Perkins tonometer is placed on a spring-loaded mechanism in a portable hand unit to allow its use for patients in a supine position. Earlier research has shown that daytime sitting and supine Perkins tonometry measurements are close to that of Goldmann tonometry. ${ }^{26}$

To date little prior data have evaluated together the 24-h intraocular pressure using Goldmann tonometry in the sitting position compared with nighttime Perkins tonometry in the supine position. Thus, this investigation has concentrated on using Perkins tonometry to measure nighttime supine intraocular pressures and comparing these values to daytime and nighttime sitting Goldmann intraocular pressure values on a large cohort of patients.

This study showed that the mean sitting intraocular pressure recorded at 1000, 2200, 0200, and 0600 hours was significantly lower $(22.2 \mathrm{~mm} \mathrm{Hg})$ than that measured in the supine position $(23.5 \mathrm{~mm} \mathrm{Hg})$. Further, with regard to specific time points, the pressure was significantly higher in the supine than sitting position at three individual time points $(1000,2200$, and 0200 hours) $(P \leqslant 0.006)$, but not at 0600 hours $(P=0.3)$. These data help to consolidate earlier evidence that, at the same time

Table 3 Maximum daytime sitting pressures measured within different intervals of the maximum nighttime supine pressures (sitting and supine)

\begin{tabular}{|c|c|c|c|c|}
\hline $\begin{array}{l}\text { Nighttime IOP } \\
\text { elevation above } \\
\text { daytime peak } \\
(\mathrm{mm} \mathrm{Hg})\end{array}$ & $\begin{array}{l}\text { Per cent of sitting daytime: } \\
\text { right eyes with IOP < than } \\
\text { indicated level in } \\
\text { column } 1(\%)\end{array}$ & $\begin{array}{c}\text { Per cent of sitting daytime: } \\
\text { left eyes with IOP < than } \\
\text { indicated level in } \\
\text { column } 1(\%)\end{array}$ & $\begin{array}{c}\text { Per cent of sitting and supine } \\
\text { daytime: right eyes with } \\
\text { IOP }<\text { than indicated level } \\
\text { in column } 1(\%)\end{array}$ & $\begin{array}{c}\text { Per cent of sitting and supine } \\
\text { daytime: left eyes with } \\
\text { IOP < than indicated level } \\
\text { in column } 1(\%)\end{array}$ \\
\hline$\leqslant 0$ & 61 & 57 & 65 & 61 \\
\hline+1 & 11 & 12 & 13 & 14 \\
\hline+2 & 14 & 9 & 11 & 10 \\
\hline+3 & 3 & 8 & 3 & 6 \\
\hline+4 & 2 & 3 & 3 & 4 \\
\hline+5 & 4 & 9 & 3 & 5 \\
\hline+6 & 2 & 1 & 1 & 0 \\
\hline+7 & 1 & 0 & 1 & 0 \\
\hline+8 & 1 & 0 & 0 & 0 \\
\hline+9 & 1 & 0 & 0 & 0 \\
\hline
\end{tabular}

Abbreviation: IOP, intraocular pressure. 
point, supine pressure measurements are generally higher than sitting pressures in patients with glaucoma or ocular hypertension. ${ }^{19}$ The additional elevation of pressure in the supine position may be due to increased episcleral venous pressure in the supine position, which might further inhibit conventional outflow facility ws a sitting position. ${ }^{26}$ However, the mean pressure elevation in the supine position recorded in our study was less than observed in a number of prior papers. ${ }^{19,34,35}$

When we evaluated our results for differences between day and nighttime sitting pressures, we found that the intraocular pressure across three daytime points (1000, 1400, and 1800 hours) was greater $(23.6 \mathrm{~mm} \mathrm{Hg})$ compared with the pressure measured across the three nighttime points (2200, 0200, and 0600 hours) $(21.5 \mathrm{~mm} \mathrm{Hg})$. Further, the majority of patients showed their sitting peak pressure in the daytime and their trough pressure at night. These data help confirm prior studies that have indicated that untreated sitting intraocular pressure values are generally lower in the night. ${ }^{4,36}$

According to this study, even nighttime supine measurements, with their accompanying higher pressures compared with sitting pressures at the same time point, did not elevate the mean pressure statistically above daytime levels. However, only $70 \%$ of patients showed a peak sitting daytime pressure that was within $1.0 \mathrm{~mm} \mathrm{Hg}$ of the highest nighttime sitting or supine measurement. Even including the data from one daytime supine measurement failed to further help daytime pressures predict peak nighttime supine or sitting pressures.

A number of prior studies have indicated the importance of only a $1.0 \mathrm{~mm} \mathrm{Hg}$ change in pressure long term in the progression rate of open-angle glaucoma. ${ }^{37-40}$

These data are important because they imply that physicians potentially may be missing elevated intraocular pressures, at least in untreated patients, by routinely measuring only sitting, or even a single supine measurement, in the daytime. Importantly, it remains unclear how glaucoma treatment might alter the 24-h pressure characteristics and the association of sitting daytime to either supine or sitting nighttime pressures. Nonetheless, Jonas and co-workers ${ }^{41}$ have found earlier that the peak pressure often occurs outside normal office hours. Therefore, the practical significance of these findings is that for patients who suffer glaucomatous progression with seemingly well-controlled intraocular pressure, a physician may consider checking nighttime sitting and supine pressures to further evaluate the adequacy of the pressure control.

It is worthwhile to consider that the most exact way to measure the intraocular pressure, either in a sitting or supine position, still remains unclear. Ideally, the most precise way to measure pressure would be from an intraocular manometric device, which is currently impractical, and as yet unproven, for routine clinical use. ${ }^{42}$ At least for sitting pressure measurements, Goldmann tonometry, although imperfect, remains the gold standard for clinical intraocular pressure measurements. $^{22}$

This 24-h study suggests that with Perkins applanation tonometry, the untreated mean supine intraocular pressures are not higher at night than in the daytime than with sitting Goldmann applanation tonometry. However, the highest daytime sitting intraocular pressure measurement does not consistently predict the highest nighttime sitting or supine intraocular pressure value.

This study did not evaluate supine vs sitting pressures in patients treated with various anti-glaucoma medications. It remains unknown whether some glaucoma medicines are more effective in minimizing the elevation of pressures in the supine position. Further, pressure changes may have occurred between sitting and supine positions from the use of similar, albeit different, tonometers and even from the short delay between measurements. Future research is needed to clarify, which topical medications might be better for patients in the supine position. More recently, research efforts are concentrated on developing better ways to continuously measure the intraocular pressure day and night as well as to better determine which time points during the daytime might better predict nighttime sitting and supine pressure. In addition, sitting and supine pressure should be compared ideally with even better techniques than Goldmann application tonometry.

\section{Summary}

What was known before

- IOP generally is higher during the daytime than in the nighttime.

- Some studies demonstrated higher IOPs in untreated patients at night compared with daytime.

- Controversy exists whether IOP is higher in the daytime or nighttime and what is the best method to measure nighttime IOP.

What this study adds

- The untreated mean supine IOPs with Perkins applanation tonometry are not higher at night than daytime sitting Goldmann applanation tonometry.

- The highest daytime sitting IOP measurement does not consistently predict the highest nighttime sitting or supine IOP.

\section{Conflict of interest}

The authors declare no conflict of interest. 


\section{References}

1 Kida T, Liu JH, Weinreb RN. Effect of 24-h corneal biomechanical changes on intraocular pressure measurement. Invest Ophthalmol Vis Sci 2006; 47: 4422-4426.

2 Liu JH, Kripke DF, Twa MD, Hoffman RE, Mansberger SL, Rex KM et al. Twenty-four-hour pattern of intraocular pressure in the aging population. Invest Ophthalmol Vis Sci 1999; 40: 2912-2917.

3 Weinreb RN, Liu JH. Nocturnal rhythms of intraocular pressure. Arch Ophthalmol 2006; 124: 269-270.

4 Quaranta L, Gandolfo F, Turano R, Rovida F, Pizzolante T, Musig A et al. Effects of topical hypotensive drugs on circadian IOP, blood pressure, and calculated diastolic ocular perfusion pressure in patients with glaucoma. Invest Ophthalmol Vis Sci 2006; 47: 2917-2923.

5 Konstas AG, Nakos E, Tersis I, Lallos NA, Leech JN, Stewart WC. A comparison of once-daily morning vs evening dosing of concomitant latanoprost/timolol. Am J Ophthalmol 2002; 133: 753-757.

6 García-Feijoo J, Martínez-de-la-Casa JM, Castillo A, Méndez C, Fernández-Vidal A, García-Sánchez J. Circadian IOP-lowering efficacy of travoprost $0.004 \%$ ophthalmic solution compared to latanoprost $0.005 \%$. Curr Med Res Opin 2006; 22: 1689-1697.

7 Konstas AG, Mikropoulos D, Haidich AB, Ntampos KS, Stewart WC. 24-h intraocular pressure control with the travoprost/timolol fixed combination compared with travoprost when both are dosed in the evening in primary open-angle glaucoma. Br J Ophthalmol 2009; 93: 481-485.

8 Konstas AG, Tsironi S, Vakalis AN, Nasr MB, Stewart JA, Nelson LA et al. Intraocular pressure control over $24 \mathrm{~h}$ using travoprost and timolol fixed combination administered in the morning or evening in primary open-angle and exfoliative glaucoma. Acta Ophthalmol Scan 2009; 87: 71-76.

9 Konstas AG, Mikropoulos D, Kaltsos K, Jenkins JN, Stewart WC. 24-h intraocular pressure control obtained with evening versus morning dosed travoprost in primary openangle glaucoma. Ophthalmology 2006; 113: 446-450.

10 Barkana Y, Anis S, Liebmann J, Tello C, Ritch R. Clinical utility of intraocular pressure monitoring outside of normal office hours in patients with glaucoma. Arch Ophthalmol 2006; 124: 793-797.

11 Orzalesi N, Rossetti L, Bottoli A, Fogagnolo P. Comparison of the effects of latanoprost, travoprost, and bimatoprost on circadian intraocular pressure in patients with glaucoma or ocular hypertension. Ophthalmology 2006; 113: 239-246.

12 Hughes E, Spry P, Diamond J. 24-h monitoring of intraocular pressure in glaucoma management: a retrospective review. J Glaucoma 2003; 12: 232-236.

13 Wilensky JT. The role of diurnal pressure measurements in the management of open angle glaucoma. Curr Opin Ophthalmol 2004; 15: 90-92.

14 Orzalesi N, Rossetti L, Invernizzi T, Bottoli A, Autelitano A. Effect of timolol, latanoprost, and dorzolamide on circadian IOP in glaucoma or ocular hypertension. Invest Ophthalmol Vis Sci 2000; 41: 2566-2573.

15 Fogagnolo P, Rossetti L, Mazzolani F, Orzalesi N. Circadian variations in central corneal thickness and intraocular pressure in patients with glaucoma. Br J Ophthalmol 2006; 90: $24-28$.

16 Rossetti L, Karabatsas CH, Topouzis F, Vetrugno M, Centofanti M, Boehm A et al. Comparison of the effects of bimatoprost and a fixed combination of latanoprost and timolol on circadian intraocular pressure. Ophthalmology 2007; 114: 2244-2251.

17 Tajunisah I, Reddy SC, Fathilah J. Diurnal variation of intraocular pressure in suspected glaucoma patients and their outcome. Graefes Arch Clin Exp Ophthalmol 2007; 245: 1851-1857.

18 Liu JH, Bouligny RP, Kripke DF, Weinreb RN. Nocturnal elevation of intraocular pressure is detectable in the sitting position. Invest Ophthalmol Vis Sci 2003; 44: 4439-4442.

19 Liu JH, Kripke DF, Weinreb RN. Comparison of the nocturnal effects of once-daily timolol and latanoprost on intraocular pressure. Am J Ophthalmol 2004; 138: 389-395.

20 Lagerlöf $\mathrm{O}$. Airpuff tonometry versus applanation tonometry. Acta Ophthalmol (Copenh) 1990; 68: 221-224.

21 Stewart WC. Clinical Practice of Glaucoma. SLACK, Inc.: Thorofare, 1990, pp 255-297.

22 Ritch R. The Glaucomas. Mosby-Year Book, Inc.: St Louis, 1996, pp 1426-1430.

23 Stewart WC, Holmes KT, Johnson MA. Washout periods for brimonidine $0.2 \%$ and latanoprost $0.005 \%$. Am J Ophthalmol 2001; 131: 798-799.

24 Stroman GA, Stewart WC, Stewart JA, Deitz TM. Safety of beta-adrenergic blocker washout period in clinical trials Acta Ophthalmol Scand 1997; 75: 94-95.

25 Schlecht LP, Brubaker RF. The effects of withdrawal of timolol in chronically treated glaucoma patients. Ophthalmology 1988; 95: 1212-1216.

26 Baskett JS, Goen TM, Terry JE. A comparison of Perkins and Goldmann applanation tonometry. J Am Optom Assoc 1986; 57: 832-834.

27 Krieglstein GK, Waller WK. Goldmann applanation versus hand-applanation and schiötz indentation tonometry. Albrecht Von Graefes Arch Klin Exp Ophthalmol 1975; 194: 11-16.

28 Chiara GF, Semes LP, Potter JW, Cutter GR, Tucker WR. Portable tonometers: a clinical comparison of applanation and indentation devices. J Am Optom Assoc 1989; 60: 105-110.

29 Wingert TA, Bassi CJ, McAlister WH, Galanis JC. Clinical evaluation of five portable tonometers. J Am Optom Assoc 1995; 66: 670-674.

30 Wozniak K, Köller AU, Spörl E, Böhm AG, Pillunat LE. Intraocular pressure measurement during the day and night for glaucoma patients and normal controls using Goldmann and Perkins applanation tonometry. Ophthalmologe 2006; 103: 1027-1031.

31 Duff GR. A double-masked crossover study comparing the effects of carteolol 1 and $2 \%$ on intraocular pressure. Acta Ophthalmol (Copenh) 1987; 65: 618-621.

32 Mundorf TK, Cate EA, Sine CS, Otero DW, Stewart JA, Stewart WC. The safety and efficacy of switching timolol maleate $0.5 \%$ solution to timolol hemihydrate $0.5 \%$ solution given twice daily. J Ocul Pharmacol Ther 1998; 14: 129-135.

33 Book SA. Essentials of Statistics. McGraw-Hill, Inc.: New York, 1978, pp 205-215.

34 Kiuchi T, Motoyama Y, Oshika T. Relationship of progression of visual field damage to postural changes in intraocular pressure in patients with normal-tension glaucoma. Ophthalmology 2006; 113: 2150-2155.

35 Liu JH, Kripke DF, Hoffman RE, Twa MD, Loving RT, Rex $\mathrm{KM}$ et al. Nocturnal elevation of intraocular pressure in young adults. Invest Ophthalmol Vis Sci 1998; 39: 2707-2712.

36 Stewart WC, Konstas AGP, Nelson LA, Kruft B. Metaanalysis of 24-h intraocular pressure studies evaluating the 
efficacy of glaucoma medicines. Ophthalmology 2008; 115: 1117-1122.

37 Stewart WC, Kolker AE, Sharpe ED, Day DG, Konstas AG, Hollo $\mathrm{G}$ et al. Long-term progression at individual mean intraocular pressure levels in primary open-angle and exfoliative glaucoma. Eur J Ophthalmol 2008; 18: 765-770.

38 Ocular Hypertension Treatment Study Group and the European Glaucoma Prevention Study Group. The accuracy and clinical application of predictive models for primary open-angle glaucoma in ocular hypertensive individuals. Ophthalmology 2008; 115: 2030-2036.

39 Heijl A, Bengtsson B, Chauhan BC, Lieberman MF, Cunliffe I, Hyman L et al. A comparison of visual field progression criteria of 3 major glaucoma trials in early manifest glaucoma trial patients. Ophthalmology 2008; 115: 1557-1565.

40 Spry PG, Bates AB, Johnson CA, Chauhan BC. Simulation of longitudinal threshold visual field data. Invest Ophthalmol Vis Sci 2000; 41: 2192-2200.

41 Jonas JB, Budde W, Stroux A, Oberacher-Velten IM, Jünemann A. Single intraocular pressure measurements and diurnal intraocular pressure profiles. Am J Ophthalmol 2005; 139: 1136-1137.

42 Prata Jr JA, Mérmoud A, LaBree L, Minckler DS. In vitro and in vivo flow characteristics of glaucoma drainage implants. Ophthalmology 1995; 102: 894-904. 